\title{
LA GEOMETRÍA DEL DESEO EN TRES HISTORIAS DE AMOR
}

\author{
"Eran meditaciones sobre la vida, el amor, la vejez y la muerte: \\ ideas que habian pasado muchas veces aleteando como pájaros \\ nocturnos sobre su cabeza, pero que se le desbarataban en un \\ reguero de plumas cuando trataba de atraparlas".
}

(Gabriel García Márquz, El amor en los tiempos del cólera)

Algunos críticos consideran que sin amor, con todas sus complicaciones, la novela, como género, no habria alcanzado en tan pocas centurias el desarrollo que hoy exhibe. Por ello quizá sea una perogrullada decir que este es uno de los temas más recurrentes en toda la narrativa de García Márquez. Por supuesto que se ha intensificado mucho más en sus últimas novelas por esta intencionalidad del autor que se percibe explícitamente desde el mismo título ${ }^{1}$. Pero ha sido una preocupación constante desde sus primeras narraciones. El objetivo del presente ensayo es el de analizar tres momentos de esa preocupación a partir de tres relatos diferentes. El primer texto seleccionado es el cuento "Muerte constante más allá del amor"2. Su protagonista ejemplifica una historia de amor en donde eros y thanatos están intensamente presentes y en donde el amor se revela incapaz de superar a la soledad definitiva que es la muerte. El segundo texto es el considerado erróneamente por algunos críticos como el clásico y único de García Márquez para el tratamiento del tema: El amor en los tiempos del cólera $^{3}$. El objetivo buscado es el de analizar el amor -en términos de Girard- como un deseo triangular. Finalmente, Del amor y otros demonios representa un nuevo acercamiento a la pasión amorosa en un contexto en donde religión, eros, y muerte se encuentran determinando no sólo la acción narrativa sino el destino mismo de los personajes.

\section{A. Amor y soledad en "Muerte constante más allá del amor"}

Lo primero que llama la atención al lector de este cuento de García Márquez es la relación de intertextualidad que se establece a partir del título con el famosísimo soneto de Francisco Quevedo, "Amor constante más allá de la muerte", considerado por Octavio Paz como el poema de amor más sublime jamás escrito en castellano. Podría pensarse que ese juego retórico

1 Ese es el testimonio del mismo autor sobre su intencionalidad narrativa: “En algún momento, hace algunos años, me di cuenta de que queria ser sincero. He sacrificado toda mi vida para pensar en términos más ideológicos o intelectuales dejando un poco de lado los sentimientos y sensaciones. Quería romper con todo esto y escribir un libro que fuera totalmente romántico. Sin tener temor alguno de usar los elementos del romanticismo: melodrama y sentimentalismo", Gabriel García Márquez en la entrevista con Pete Hamill, "Love and solitude", Vanity Fair, 131 (March 1988): 131. (La traducción es mia)

2 Gabriel Garcia Márquez, La increible y triste historia de la cándida Eréndira y su abuela desalmada: Siete cuentos. México: Hermes, 1972.

3 “[...] en el librero de García Márquez, la palabra amor es de Florentino Ariza y Fermina Daza, de nadie más" (Stavans Illans, "Gabo en caricatura", en Revista Época, 163 (México, 1994): 75. 
con las palabras amor/muerte constituye la respuesta de García Márquez a la propuesta quevediana de un amor que traspasa las puertas de la temporalidad y alcanza los espacios de la eternidad. La gran limitación y causa de desasosiego del amante es la temporalidad. Así como un día ese sentimiento ha nacido, también algún día, tal vez el menos deseado, también morirá. Quevedo propone a su amada un amor constante, es decir un amor que pueda burlar el estrecho margen impuesto por el tiempo. "El alma, llama enamorada, viola 'la ley severa' que separa el mundo de los muertos del de los vivos [...] Aunque el cuerpo se deshace en materia informe, esa materia está animada. El poder que la anima y le infunde una terrible eternidad es el amor, el deseo"4. Desde el título, García Márquez quisiera expresar lo contrario: llegada la muerte no hay posibilidad alguna para el amor. La constante humana no es el amor cuanto la muerte.

Por ello en este relato, desde la primera oración aparecen unidos la muerte y el encuentro inicial con el objeto del amor: "Al senador Onésimo Sánchez le faltaban seis meses y once días para morirse cuando conoció a la mujer de su vida". Thanatos y Eros entrelazados. El destino de muerte trazado por los dioses y señalado por los médicos tres meses antes parece no alterar las actividades rutinarias del senador; en cambio, una mujer, Laura Farina, tiene el poder que nadie hubiera sospechado: "que alli viviera alguien capaz de torcer el destino de nadie". En realidad, no es su poder sino el del amor en ese enfrentamiento a la soledad de la muerte.

$Y$ es que el senador, rodeado siempre de gente, experimenta la más atroz acechanza de la soledad. Él mismo asi lo ha querido "pues habia decidido padecer a solas su secreto, sin ningún cambio de vida". Pero aparece Laura, quien con su "belleza inverosimil era más imperiosa que su dolor". Es hija de un prófugo francés y de una negra de Paramaribo. El padre "tenia razones para suponer que estaba criando a la mujer más bella del mundo". Cuando el senador la ve y descubre su belleza no le queda más remedio que exclamar: "Carajo, las cosas que se le ocurren a Dios". Se inicia el proceso: la forma sensible apela al senador. Pronto se hace evidente que sus almas comparten el sentimiento de soledad ${ }^{5}$. Ella es la única rosa en ese pueblecito con nombre de burla: "El rosal del Virrey". Ambos son aries y según el senador ese es "el signo de la soledad".

Precisamente, ese rasgo común es el que permite a Laura pasar de objeto erótico al servicio de los intereses del padre, a sujeto del deseo en la interrelación con el senador Onésimo Sánchez. La hija, en su papel de objeto erótico, es enviada como una carnada a ese político promesero que una vez pasadas las elecciones olvida los compromisos adquiridos con sus electores. Pero esta vez se pasa de la oralidad a la escritura para que el compromiso adquiera el sentido de ineludible. Para que pueda gozar ese objeto erótico tiene que mandarle a Nelson Farina "un compromiso escrito de que le va a arreglar su situación". Sólo así le enviará la llave del cinturón de castidad que le ha colocado a su hija.

4 Octavio Paz, La llama doble: amor y erotismo, Bogotá: Seix Barral, 1994: 65 y 67.

5 "Tocante al hecho de que nazca el amor, en la mayoría de los casos, por la forma bella, es evidente que, siendo el alma bella, suspira por todo lo hermoso y siente inclinación por las perfectas imágenes. En cuanto ve una de ellas, alli se queda fija. Si luego distingue tras esa imagen alguna cosa que le sea afin, se une con ella y nace el verdadero amor; pero si no se distingue tras la imagen nada afin a sí, su afección o pasa de la forma y se queda en apetito carnal" (Ibn Hazm de Córdoba, El collar de la paloma, Madrid: Alianza Editorial, 1997:139). 
Sin embargo, el problema mayor del Senador no es de tipo sexual sino de soledad y de muerte. Por ello, y porque Laura comparte ese sentimiento de aislamiento y soledad experimentados en ese pueblecito ilusorio de donde no pueden salir por falta de una cédula de ciudadanía, al final el senador la retiene: "Olvídate de la llave -dijo- y duérmete un rato conmigo. Es bueno estar con alguien cuando uno está solo". Ante esta situación, Laura como sujeto amoroso "lo acostó en su hombro con los ojos fijos en la rosa".

Al final del relato se cierra el círculo: "Seis meses y once días después había de morir en esa misma posición, pervertido y repudiado por el escándalo público de Laura Farina”. Los dos como sujetos amorosos han tomado la decisión de vivir su amor intimo sin importar las implicaciones públicas de sus actos. Sin embargo, pasado el tiempo pronosticado tan puntualmente por los médicos no hay la esperanza quevediana de un "amor constante más allá de la muerte", sino la convicción muy garciamarquiana de que ante la absoluta soledad que impone la muerte ni siquiera el amor logra ser un paliativo. Este enamorado se encuentra muy lejos de aquél que consideraba que la brevedad del gozo del amor le causaria la muerte, si bien no le importaría con tal de que le llegara en los brazos de su amiga ${ }^{6}$. Al contrario de este amante medieval, Onésimo Sánchez termina sus días "llorando de la rabia de morirse sin ella”. Soledad constante más allá del amor. García Márquez, por medio de este cuento, ejemplifica certeramente "que el amor no vence a la muerte: es una apuesta contra el tiempo y sus accidentes" ${ }^{7}$. Y es preciso recordar que para el poeta Ibn Hazm de Córdoba, "el amor es, en sí mismo, un accidente"8.

\section{B. El deseo triangular en $\mathrm{El}$ amor en los tiempos del cólera ${ }^{9}$}

El amor en los tiempos del cólera ha sido catalogada como una novela romántica, representativa, precisamente, de un romanticismo tardío en el caribe colombiano; según la intencionalidad autorial, tiene como objetivo mostrar el amor como herramienta básica e indispensable para lograr todas las metas. García Márquez confiesa que lo verdaderamente valioso en la novela es el análisis del amor en cualquier momento de la vida: “[...] el amor determina un comportamiento y un tipo de relación que es igual en todas las edades, lo que hace falta siempre es el amor que, si lo hay, a cualquier edad se manifiesta de igual forma"10.

Si se toma la opinión del propio autor como una más de un lector común, se entiende que otros analistas se inclinen más por pensar en $A T C$ no como un análisis del amor en todas las edades, sino más bien como una "parodia al amor romántico, a esa historia de amor con un final feliz" ${ }^{11}$. Pero, más allá de todo aquello que se ha dicho sobre el sentimiento amoroso

6 Guillaume de Lorris y Jean de Meun, El libro de la rosa, Madrid. Siruela:1986: 44.

Paz: 220.

8 Ibn Hazm de Córdoba: 128.

9 Gabriel García Márquez, El amor en los tiempos del cólera, Bogotá, Editorial La Oveja Negra, 1985. Todas las citas y alusiones a esta novela han sido tomadas de esta edición, precedidas de la abreviatura $A T C$. Los subrayados en las citas son mios.

10 Garcia Márquez en entrevista con Francese Arroyo en El País_de Madrid, reproducida en El Mundo, 25 de enero de 1986.

11 Isabel'Rodriguez Vergara, El mundo satírico de Gabriel Garcia Márquez, Madrid, Editorial Pliegos, 1999: 128-129. 
en la novela, se ha olvidado un poco ese tipo de amor que trasciende las fronteras de lo netamente romántico e idílico para convertirse en una muestra de la degradación humana: el deseo mediatizado según el Otro ${ }^{12}$.

En esta novela de García Márquez se pueden distinguir dos etapas:

Una primera etapa del amor idílico adolescente de ambos jóvenes y la deificación de Fermina (la Diosa Coronada) por parte de Florentino, que como bien lo expresa Octavio Paz, representa la etapa del reconocimiento de la mujer como persona única capaz de satisfacerle y asegurarle la felicidad ${ }^{13}$.

La segunda etapa de estos amores prohibidos comienza con el rechazo de Fermina Daza hacia Florentino. Es el momento en donde "el objeto del deseo se vuelve sujeto que me desea o que me rechaza" 14 . Ante el repudio el protagonista se obsesiona por alcanzar su objeto del deseo con más fervor. Es aquí cuando el amor pierde su autenticidad y es mediatizado por un rival. En esta segunda etapa, la teoria del deseo triangular según el Otro entra en vigencia.

En Mentira romántica y verdad novelesca, René Girard presenta al hombre moderno como un ser sin originalidad, imitador permanente de modelos hasta para la consecución de sus metas más íntimas, como el amor. Ese mediador del deseo es generalmente un rival que también desea o ya posee el objeto del deseo. En la segunda etapa de $A T C$, Florentino representa ese ser degradado que desea a Fermina a través de Juvenal. Así, el doctor Urbino se transforma en el obstáculo dentro del universo de Florentino: "El día que Florentino Ariza vio a Fermina Daza en el atrio de la catedral, encinta de seis meses y con pleno dominio de su condición de mujer de mundo, tomó la determinación feroz de ganar nombre y fortuna para merecerla. Ni siquiera se puso a pensar en el inconveniente de que fuera casada, porque al mismo tiempo decidió, como si dependiera de él, que el doctor Juvenal Urbino tenía que morir" (ATC: 163). Cada vez que Florentino desea acercarse más a su objeto (Fermina), inevitablemente se acerca más al obstáculo, imitándolo. Esta imitación secreta y disimulada causan en Florentino sentimientos encontrados que Girard llama sentimientos modernos, como son: una honda veneración y mucho rencor que se traducen en odio, al mismo tiempo que en celos y en envidias: "Los celos, hasta entonces ahogados en llanto, se hicieron dueños de su alma. Rogaba a Dios que la centella de la justicia divina fulminara a Fermina Daza cuando se dispusiera a jurar amor y obediencia a un hombre que sólo la quería para esposa como un adorno social, y se extasiaba en la visión de la novia suya o de nadie" (ATC: 144 ).

$\mathrm{Al}$ odiar a Juvenal, Florentino se odia secretamente por admirarlo ${ }^{15}$ : "Florentino Ariza no pudo resistir la punzada de dolor de que aquel hombre admirable tuviera que morirse para

12 René Girard, en su obra Mentira Romántica y verdad novelesca, afirma que el hombre moderno es un ser inauténtico, incapaz de desear por si mismo y por esta razón "mediatiza" sus deseos, razón por la cual imita modelos que lo conduzcan al su objeto del deseo. A este deseo mediatizado se le ilama deseo triangular. Para su análisis sobre el deseo triangular y la mediación, René Girard delimita su corpus con Cervantes (Don Quijote), Stendhal (El rojo y el negro), Flaubert (Madame Boyary), Proust y Dostoievski.

13 Octavio Paz, La llama doble, amor y erotismo, Barcelona, Seix Barral, 1993. Paz aclara que la deificación de la mujer en el sentimiento amoroso no obedece a otra cosa que al reconocimiento de su calidad de persona única e irrepetible. Paz, Llama: 125.

15 René Girard, Mentira romántica y verdad novelesca. Barcelona, Editorial Anagrama, 1985, pág. 17. 
que él fuera feliz" ( $A T C:$ 188). En este proceso de pasiones encontradas, Florentino acaba por parecerse a Juvenal. La rivalidad incrementa el prestigio del mediador, quien es cada vez más admirado, más odiado y más imitado.

En $A T C$, el deseo triangular se fortalece a medida que Florentino conoce de cerca la superioridad de Juvenal, el mediador, quien goza de lo que le ha sido negado a él: "Hizo alguna referencia casual a los ciclones lunáticos de junio, y de pronto, sin que viniera a cuento, habló de su esposa. No sólo la tenía como su colaboradora más entusiasta, sino como el alma misma de sus iniciativas. Dijo: "Yo no sería nadie sin ella»...al doctor Juvenal Urbino, en medio de sus tantos compromisos absorbentes, todavía le sobraba tiempo para adorar a su esposa, casi tanto como él [...] Él y aquel hombre que había tenido siempre como el enemigo personal eran víctima de un mismo destino y compartían el azar de una pasión común: dos animales de yunta uncidos al mismo yugo" (ATC: 187-188). Esta es la imagen que mejor ilustra ese deseo triangular conformado por esos dos hombres (bueyes) unidos por el amor a la misma mujer

Florentino se convierte en un ser envidioso de lo que no es y de lo que no tiene y ve, con tristeza, los otros objetos del deseo -aunque iguales o parecidos a Fermina- carentes de valor. Por esta razón se explica la paradoja que a pesar de todas las aventuras amorosas de Florentino, éste se mantuvo virgen para ella, como se lo confiesa en el último capítulo de la novela: "Es que me he mantenido virgen para ti" (ATC: 327$)$.

Otro aspecto importante del deseo triangular es la incomunicabilidad de la experiencia amorosa. El hecho es que el hombre moderno tan orgulloso de todo cuanto afecta la manera en que es percibido socialmente, se autocondena a la más amarga y triste soledad en lo que tiene que ver con su fuero intimo. “¿Por qué los hombres son incapaces de aliviar sus sentimientos compartiéndolos?" 16 . Florentino Ariza calla su sufrimiento porque esta incomunicabilidad sublimiza el deseo que por definición tiene el rasgo de la más absoluta subjetividad: "Leona Cassiani pasó por su oficina, y le pareció una ocasión única para revelarle el secreto sin más vueltas, como reventar un nudo de golondrinos que no lo dejaba vivir: ahora o nunca [...] Entonces supo Florentino Ariza que en alguna noche incierta del futuro, en una cama feliz con Fermina Daza, iba a contarle que no había revelado el secreto de su amor ni siquiera a la única persona que se había ganado el derecho de saberlo. No: no había de revelarlo jamás" ( $A T C:$ 189).

El deseo según el Otro siempre es el deseo de ser $\mathrm{Otro}^{17}$. Y Florentino así lo logra. Al morir Juvenal desaparece el obstáculo y al no existir más una mediación. Florentino ocupa el tan anhelado lugar de Juvenal, a quien ha admirado e imitado tanto que termina por parecérsele: "En lugar de los atuendos fúnebres de toda la vida, llevaba unos zapatos blancos muy cómodos, pantalón y camisa de hilo con cuello abierto y manga corta y su monograma bordado en el bolsillo del pecho. Llevaba además una gorra escocesa, también blanca, y un dispositivo de lentes oscuros superpuestos a sus eternos espejuelos de miope" (ATC: 319 ).

16 Girard: 56.

17 Girard: 79. 
En algunos casos de deseo triangular, al alcanzar el objeto del deseo, éste se desacraliza automáticamente, reduciéndose a sus propiedades objetivas, es decir, hay una especie de desilusión ${ }^{18}$. En $A T C$ no hay desilusión, pero si hay una objetivización del sentimiento amoroso que le permite a Florentino ver a una Fermina anciana, desposeída de toda belleza y lozania del pasado: "Florentino Ariza se estremeció: en efecto, como ella misma lo había dicho, tenía el olor agrio de la edad [...] Tenía los hombros arrugados, los senos caídos y el costillar forrado de un pellejo pálido y frío como el de una rana" (ATC: 323 y 326).

Sin embargo, a pesar de ser un imitador para todo ${ }^{19}$, Florentino tiene un momento de lucidez en el cual reconoce de manera indirecta no haber amado a Fermina: "Como una compensación del destino, también fue en el tranvía de mulas donde Florentino Ariza conoció a Leona Cassiani, que fue la verdadera mujer de su vida, aunque ni él ni ella lo supieron nunca, ni nunca hicieron el amor" (ATC: 179). Teme que al revelarle su secreto se descubra la farsa montada a través del otro, o su cobardía para revelarle su verdadero objeto amoroso: "En el otro lado de la ciudad estaba Leona Cassiani sola y libre [...] pero comprendió que ella era demasiado inteligente y se amaban demasiado para que él fuera a llorar en su regazo sin revelarle el motivo" (ATC: 276).

Por otra parte, Fermina reconoce haber sido muy feliz - con o sin amor- junto a Juvenal y no haber amado nunca a Florentino: "[...] hacia donde quiera que se revolvia su memoria de aquellos tiempos, tropezaba con el recuerdo de Florentino Ariza. Sin embargo, siempre tuvo bastante serenidad para darse cuenta de que no eran recuerdos de amor, ni de arrepentimiento, sino la imagen de un sinsabor que le dejaba un rastro de lágrimas" (ATC: 218). Ambos comparten la plena conciencia de que su aventura juvenil no llegó a ser verdaderamente una vivencia del amor: "La memoria del pasado no redimía el futuro como él se empeñaba en creer. Al contrario, fortalecía la convicción que Fermina Daza tuvo siempre de que aquel alboroto febril de los veinte años había sido cualquier cosa muy noble y muy bella, pero no fue amor." (ATC: 306 ). Muy contrariamente a lo que un lector distraido podria pensar, Juvenal y Fermina -aunque se casaron sin amarse- no tuvieron obstáculos para inventarse un buen amor, si bien "nada en este mundo era más difícil que el amor" (ATC: 217). Sin duda alguna, existió amor entre ellos y lo vivieron a plenitud, con todos los altibajos del "amor domesticado" (ATC: 35): Es comprensible, entonces, que al final, cuando la muerte es inminente, Juvenal se despida reiterándole su amor: "la miró por última vez para siempre jamás con los ojos más luminosos, más tristes y más agradecidos que ella no le vio nunca en medio siglo de vida en común, y alcanzó a decirle con el último aliento: «Sólo Dios sabe cuánto te quise»" (ATC: 49$)$.

Girard: 83. En el análisis girardiano se aclara que ni en El Quijote ni en Mme. Bovary se observa esa decepción metafisica que si es bien notable en Standhal y en Dovstoieski.

19 Recuérdese que Florentino tenia como modelo los poetas colombianos románticos de principios del siglo XX, a quienes imitaba en la lectura y escritura de versos y hasta en su apariencia: "...sus atuendos sombrios, las levitas anacrónicas, el sombrero único, las corbatas de cintas de poetas de la merceria de su madre, el paraguas siniestro" (217). Este otro tipo de mediación llamada externa según Girard, es aquella en la que se imitan modelos exteriores a la vida del sujeto. Por ejemplo, Don Quijote, cuyo modelo de caballeria a imitar era Amadis de Gaula. 
De hecho, el amor de Fermina por Florentino hacia el final de la novela, es un amor nuevo y maduro que nace después de la viudez. Así, Fermina Daza, personaje consentido de García Márquez ${ }^{20}$, se sale con la suya toda su vida: se casa con el respetado doctor Juvenal Urbino de la Calle, logrando una posición importante en la sociedad cartagenera de principios de siglo. Este enlace le proporciona una vida de prestigio, lujos y comodidades que perduran aún después de la muerte de su marido. Finalmente, en la vejez, García Márquez le confiere a Fermina la alegría del amor otoñal y una compañía para sus últimos años. En este momento, Fermina redescubre a Florentino y se enamora de él. De un hombre diferente sin los lirismos empalagosos del pasado: "De ese modo se le revelaba un Florentino Ariza desconocido, con una clarividencia que no correspondia a las esquelas febriles de su juventud ni a su conducta sombria de toda la vida" (ATC: 289). Por su parte, Florentino había trazado su estrategia a imitación de una guerra final en donde "todo tenia que ser diferente para suscitar nuevas curiosidades, nuevas intrigas, nuevas esperanzas, en una mujer que ya habia vivido a plenitud una vida completa" (ATC: 284).

A pesar de que al final, Florentino es percibido por Fermina como distinto, no deja de ser sintomático que ahora ocupa el lugar de Juvenal Urbino. Es distinto al Florentino de los veinte años, pero tal vez muy parecido al marido de toda la vida. Al final de la novela, el viaje por el río Magdalena con Florentino es como la continuación de ese viaje de bodas a Europa, sólo que para el héroe novelesco, el mediador ha desaparecido, pero no sin antes revelarle, sin querer, el secreto maravilloso que le permite ahora acercarse a Fermina. De suerte que El amor en los tiempos del cólera se revela como una novela en la que se observa con claridad el fenómeno del deseo triangular, es decir, esa manera de desear del hombre moderno, imitador incansable, temeroso de actuar de manera auténtica. Su vida entera se convierte en una falacia puesto que "la mentira es lo que mantiene el deseo triangular"21. La triada garciamarquiana ejemplifica con fineza el funcionamiento de la oscura máquina del deseo que con magistral claridad se describe en la novela Yo El Supremo: "El hombre es idiota. Nada sabe hacer sin copiar, sin imitar, sin plagiar, sin remedar. Podria ser incluso que el hombre hubiese inventado la generación por coito después de ver copular a la cigarra"22. Y cuando Florentino completa perfectamente la imitación del mediador ocurre la metamorfosis del deseo. Al final, Fermina y Florentino no se sienten ni como novios recientes ni como amantes tardíos pues ahora "transcurrian en silencio como dos esposos escaldados, más allá de las trampas de la pasión, más allá de las burlas brutales de las ilusiones y los espejismos de los desengaños: más allá del amor" ( $A T C: 470$ ). El héroe romántico, entonces, experimenta el carácter deceptivo del deseo cuando su objeto es "repentinamente desacralizado por la posesión y reducido a sus propiedades objetivas" 23 . No queda otra posibilidad diferente a ese ir y venir en un interminable viaje circular que conforma "toda la vida".

20 Según el testimonio del autor, "la fuerte es ella, Fermina Daza. La novela es ella". (Entrevista con Francese Arroyo en El Pais de Madrid, reproducida en El Mundo, 25 de enero de 1986).

21 Girard: 57.

22 Augusto Roa Bastos, Yo El Supremo, Bogotá, Editorial La Oveja Negra, 1985: 136.

Girard: 83. 


\section{El amor: "el más terrible de todos" los demonios}

Al concluir la novela Del amor y otros demonios (1994) ${ }^{24}$, al lector no le queda duda alguna que su protagonista, Sierva María de Todos los Ángeles, fue encontrada "muerta de amor". La mordida del perro es simplemente un pretexto para poner en funcionamiento toda la fabricación novelesca; pero a medida que ésta avanza se tiene la certeza de que Sierva Maria muere por otro tipo de rabia, la que le produce el abandono de que ha sido objeto, pues sin explicación alguna para ella, su amado, su objeto del deseo, ha desaparecido. ${ }^{25}$ "Sierva María no entendió nunca qué fue de Cayetano Delaura, por qué no volvió con su cesta de primores de los portales y sus noches insaciables" (DA: 197). Ella puede soportar todos los vejámenes que implica el exorcismo, pero no la pérdida de aquél que ha permitido que en su interior se instale el demonio del amor. "La separación es hermana de la muerte" 26 . Sin reparo alguno por la posible acusación de romanticismo sensiblero y lloroso, el narrador nos dice que Sierva Maria fue encontrada "muerta de amor". Se le pide al lector que vuelva a creer que "aumentan de tal suerte en ocasiones las cuitas de amor, flaquea tanto la naturaleza del amante y tanto crece la angustia, que pueden ser causa de muerte y de dejar el mundo"27.

Desde el título de la novela se abre ante el lector un horizonte de expectativas que gira alrededor de una historia de amor y la presencia de lo demoníaco. Pero ya ese sintagma nominal implica que el amor es un demonio. $O$, en otras palabras, que el amor en sí tiene un sentido demoniaco que se intensifica en el caso de Sierva Maria de Todos los Ángeles por cuanto el objeto de su amor resulta ser no un médico, como ella piensa al comienzo, sino un consagrado a Dios ${ }^{28}$.

Paradójicamente, Sierva María es estigmatizada como portadora de todos los demonios. El perro furioso de la Inquisición, encarnado en el obispo Don Toribio de Cáceres y Virtudes, condena sin apelación alguna a Sierva María a causa de que representa la otredad que empecinadamente la cultura oficial se niega a reconocer. En el contexto Colonial, ella representa la verdadera libertad, pues "en aquel mundo opresivo en el que nadie era libre, Sierva María lo era: sólo ella, y sólo alli." (DA: 19). Y contra esa libertad que incluye la de amar se arma todo el dispositivo oficial que gira en torno al eje de la paganización y demonización. Según el obispo, Sierva María es presa de "convulsiones obscenas" y ladra "en jerga de idólatras". La niña de doce años es convertida, así, en el enemigo que es preciso destruir. La Iglesia tiene que exhibir todo su poder para luchar contra el poder de las tinieblas. En medio de este enfrentamiento, en total abandono y orfandad, queda Sierva María.

Entonces, aparece en escena como salido de Las mil y una noches ("como un genio liberado de una botella" [DA: 77]), el padre Cayetano Alcino del Espíritu Santo Delaura y Escu-

24 Todas las citas a esta obra se harán en el mismo texto del trabajo, precedidas dela abreviatura DA, y según la edición señalada en la bibliografía.

25 Para Abrenuncio no habia posibilidad de que después de ciento cincuenta dias la niña contrajera la rabia. "El único riesgo posible, concluyó Abrenuncio, era que muriera como tantos otros por la crueldad de los exorcismos. Efectivamente, estos incluian el corte de su hermosa cabellera, camisa de fuerza, y lavativas de agua bendita. Ante estos tormentos, a Sierva $\mathrm{M}^{\mathrm{a}}$ no le queda más remedio que "morir de amor"

26 Ibn Hasm de Córdoba: 275

27 Ibn Hasm de Córdoba: 332. 
dero. El obispo le encomienda "la salud de la niña". Su misión es la de iniciar los exorcismos de rigor en caso de posesión diabólica, no obstante que Delaura alega no tener "el carácter ni la formación ni la información" de los exorcistas. Pero aun esta misión ha estado precedida de un enigmático sueño con "la niña". Sierva María invade oníricamente el círculo de los deseos recónditos del joven sacerdote. Parecería que se tratara de "un caso de sugestión anímica o de pesadilla, que entra dentro del campo de los deseos reprimidos y de las fantasías del pensamiento" 29 . El proceso de idealización de "la marquesita criolla de doce años" ha comenzado en el espacio de creación estética que proporcionan los sueños ${ }^{30}$. Al mismo tiempo, podría pensarse que el fenómeno de cristalización que supone el enamoramiento, también ha empezado a producir sus efectos. ${ }^{31} \mathrm{El}$ primero en percatarse de ellos es el obispo quien no entiende cómo Delaura pudo soñar con una persona a quien nunca ha visto. Su intriga lo lleva a pedirle a Delaura que le relate ese sueño:

Era muy simple. Delaura había soñado que Sierva María estaba sentada frente a la ventana de un campo nevado, arrancando y comiéndose una por una las uvas de un racimo que tenía en el regazo. Cada uva que arrancaba retoñaba enseguida en el racimo. En el sueño era evidente que la niña llevaba muchos años frente a aquella ventana infinita tratando de terminar el racimo, y que no tenía prisa, porque sabía que en la última uva estaba la muerte. (DA: 102)

Evidentemente para el lector, el proceso de seducción se ha iniciado con este sueño. Con él, Delaura ingresa al juego de las apariencias y del artificio, al reino de los signos y del ritual, en donde tendrá que vérselas con el dominio del universo simbólico alrededor de la mujer ${ }^{32}$. Desde el punto de vista estructural, este sueño tiene varias funciones: la primera vez y como creación onírica de Cayetano revela la aparición en su subconsciente del objeto del deseo con una proyección futura; la segunda vez y como mágica recreación de Sierva María es la imagen de la fusión y coincidencia de sus mundos en el presente, que revela una clara conciencia de muerte para el inmediato futuro, pues le permite a la niña "incubar en la soledad de su celda el pánico de la muerte" (DA: 127). La tercera vez, vuelve el sueño a Sierva María con la imagen de la temporalidad en las uvas incesantemente retoñadas, pero que ahora son devoradas con la clara intención de acercarse prontamente a la muerte a causa de la desaparición del objeto del deseo.

Los artificios de seducción se intensifican cuando, Delaura va al convento y se encuentra por primera vez con la niña, cuya salud le ha sido confiada por el obispo. "Delaura la vio

"Sólo entonces supo Sierva María que Cayetano era su exorcista y no su médico" (DA: 126)

29 Es la conclusión a la cual llega Ibn Hazm luego de relatar la historia de un amigo quien se ha enamorado en sueños de una esclava a quien nunca ha visto.

30 Es conveniente recordar que en la tradición establecida por los libros sobre las artes del amor, el sueño puede ser el inicio de la aventura amorosa. Es lo que sucede al protagonista/narrador del Libro de la rosa: "Tuve un sueño hermosísimo, que me agradó mucho: no hubo nada en él que después no halla ocurrido tal como el sueño me lo había mostrado. Ahora quiero contarlo en verso para alegraros los corazones, pues así me lo pide y ordena Amor" (Madrid: Siruela, 1986: 4)

31 La imagen de la cristalización es de Stendhal y tiene que ver con la pasión, la vanidad y el deseo (Cfr. Girard: 22-26). Según Ortega y Gasset, por ese fenómeno de cristalización, el amor "para Stendhal es menos que ciego: es visionario. No sólo no ve lo real, sino que lo suplanta" (Estudios sobre el amor, Barcelona: Circulo de Lectores, 1969: 54). 
idéntica a la de su sueño" y experimentó los efectos físicos de su acercamiento al mundo enigmático de la mujer (DA: 110). El sacerdote inicia su misión atendiendo la salud del cuerpo; por ello "la revisó con el rigor de un médico" (DA:112) ${ }^{33}$. En ese primer encuentro, Sierva Maria responde con indiferencia; en el segundo, con un rechazo violento que hace parte del juego de seducción. De hecho, Delaura "mostraba sus heridas como trofeo de guerra y se burlaba del peligro de contraer la rabia" (DA:115). Y es que "nuestra noción del amor, que envuelve a la que tenemos de la mujer, se encuentra pues vinculada a una noción de sufrimiento fecundo que halaga o legitima oscuramente, en lo más secreto de la conciencia occidental, el gusto por la guerra" 34 .

Evidentemente, Delaura ha entrado en el círculo de fascinación y encantamiento que, tal vez sin quererlo, ha creado alrededor de sí Sierva María. El interés por la salud espiritual de la niña se ha desplazado a lo corporal. Este desplazamiento implica dos cosas: a) que Sierva Maria, al igual que Laura Farina, tiene el poder para torcer el destino de alguien 35 ; y b) que Cayetano ha dejado su interés por la religión y los libros (su destino parecía llevarlo a Roma como "custodio del fondo sefardita en la Biblioteca del Vaticano [DA:103]) y se ha orientado hacia el mundo de lo femenino, que en la tradición judeo-cristiana está intimamente asociado a lo demoníaco desde el Paraíso Terrenal. Evidentemente, en su escala de valores, Sierva Maria ha venido a desplazar a la Virgen Maria. El rezo y la contemplación de Sierva María se funden. Ahora musita dormido: "Dios te salve María de Todos los Ángeles". No hay duda alguna: Delaura al igual que la servidumbre del convento, pero por diferentes motivos, ha sido hechizado por el demonio del amor a esa criatura de apenas doce años. Delaura es plenamente consciente de ese desplazamiento hacia lo demoníaco y que, por lo tanto, "algo inmenso e irreparable había empezado a ocurrir en su vida" (DA: 118).

Prácticamente, el proceso de seducción de Cayetano está asegurado con la sola presencia -primero onírica, luego real- de Sierva María. En cambio, ella es seducida por la poesía de un antepasado de Cayetano, el poeta renacentista Garcilaso de la Vega ${ }^{36}$. Y es muy significativo que sea precisamente este poeta el elegido. Su poesía de profunda raíz castellana e italiana "está constituida por las vivencias de un espiritu agitado entre impulsos contradictorios, sumido en doliente conformidad o refugiado en sueños de hermosura" ${ }^{37}$. Sus sonetos en este relato garciamarquiano tienen la función de proporcionar una educación de la cual carece Sierva María por el descuido de sus padres. Pero, además, tienen una función descrip-

32 "Delaura era consciente de su torpeza para entenderse con mujeres. Le parecian dotadas de un uso de razón intransferible para navegar sin tropiezos por entre los azares de la realidad. La sola idea de un encuentro, aun con una criatura indefensa como Sierva Maria, le helaba el sudor de las manos" (DA: 104).

33 Paradójicamente, el médico se preocupa de la salud interior de Sierva Maria y por eso prescribe como la mejor medicina la felicidad. Delaura comienza su misión sanadora con un estuche de curaciones: "Ungió las heridas con bálsamos y alivió con soplos el escozor de la carne viva, admirado de la resistencia de la niña ante el dolor" (DA: 112). Rougemont: 247.

35 Sierva Maria parece reunir algunas de las características que de la nínfula se enuncian en Lolita de Vladimir Nabokov: la edad, la naturaleza demoniaca de su poder de seducción, así como también los efectos devastadores de su presencia.

Para J. M. López de Abiada, "los versos de Garcilaso no convencen como recurso 'conquistador'." (Cuadernos Hispanoamericanos, 548 (febrero 1996): 155. 
tiva del presente doloroso del enamorado y premonitoria del nuevo destino de su vida: "Por vos nací, por vos tengo la vida, por vos he de morir y por vos muero". Los cuarenta sonetos de Garcilaso le permiten a Cayetano imitar la voz del seductor para que sea "convincente, hipnótica, cadenciosa" y permita a la mujer "sacar a luz su deseo, sus fantasías", disolver sus miedos y llevarla "a aquello que él le hizo imaginar" 38 .

La poesía como instrumento de seducción permite la creación lúdica de la artificialidad textual que se inicia con el aprendizaje por repetición y que da licencia a los amantes para ir "saltando versos, pervirtiendo y tergiversando los sonetos por conveniencia, jugueteando con ellos a su antojo con un dominio de dueños" ${ }^{39}$. Esta experiencia lúdica erótico/textual es captada por la conciencia de Cayetano como una cercanía a lo demoníaco: "Una voz interior le hizo ver qué lejos había estado del diablo en sus insomnios de latín y griego, en los éxtasis de la fe, en los yermos de la pureza" (DA: 171).

El exorcista ha terminado por ser poseído por el demonio del amor, "el más terrible de todos". Así se lo confiesa al Obispo, para quien no hay revelación alguna pues se había dado cuenta que a Delaura ahora "nada de este mundo ni del otro le importaba como no fuera la imagen terrorífica de Sierva María, envilecida por el diablo" (DA: 159). Las penas de amor se apoderan totalmente de Cayetano quien inútilmente acude a los libros, al rezo, al fetichismo acompañado de hexámetros obscenos, a la autoflagelación. La poesía surge como el único remedio ante los ardores de la carne: "Pasó noches de delirio y días en vela escribiendo versos desaforados que eran su único sedante para las ansias del cuerpo" (DA: 134).

Paradójicamente, por otra parte, el estallido del deseo apasionado, verdadera posesión diabólica, está muy ligado al Espíritu Santo. Religión y amor aparecen muy unidos en el imaginario del franciscano. Por Cayetano Alcino del Espiritu Santo, corre una vena teológica que misteriosamente une a la Tercera Persona de la Santísima Trinidad con el amor. Y, por consiguiente, le otorga una amplia justificación. Por ello, en su charla con Abrenuncio, cuando el ateo médico portugués le pregunta si no teme condenarse luego de esos extremos de demencia a causa del amor, Delaura le responde: "Creo que ya lo estoy, pero no por el Espíritu Santo". "Siempre he creído que él toma más en cuenta el amor que la fe" (DA: 195). La lectura que hace de la presencia de Sierva Maria en su camino sólo se ilumina con los designios del Consolador: "A no ser que esa criatura me haya sido impuesta por el Espiritu Santo para probar la fortaleza de mi fe" (DA: 156).

La ambigüedad frente a las exigencias del deseo, motivada en buena medida por el temor a abandonar completamente el primer amor (Dios, el Espíritu Santo, la Religión), es la causa del sino trágico para Delaura. En el plano erótico, esa ambigüedad se manifiesta en la práctica de la enseñanza del poeta/soldado de un amor ardiente/honesto que "encienda al corazón y lo refrena": "... se revolcaban en cenegales de deseo hasta el límite de sus fuerzas. Exhaustos pero vírgenes" (DA: 172). En el plano teológico, la dicotomía se presenta entre ese amor a Dios, nombre del hospital a donde es enviado como castigo inquisitorial, y el amor

37 Rafael Lapesa, La trayectoria poética de Garcilaso, Madrid: Alianza Editorial, 1985: 175.

38 Francesco Alberoni, El erotismo, Barcelona: Gedisa, 1993: 105. 
de naturaleza diabólica que le inspira Sierva María, no obstante su convicción de que el amor es fruto del Espíritu Santo. En el plano del relato, es el súbito cambio que experimenta la relación con esa figura del padre/amante que simboliza don Toribio de Cáceres y Virtudes, y que abiertamente capta la imaginación popular. Al verse desplazado como parte de ese deseo triangular, el obispo "lo borró de su corazón" (DA: 161).

$\mathrm{El}$ encuentro de Cayetano con Sierva María le permite descubrir otro paraíso diferente al de la biblioteca pero cede al temor por su debilidad trágica. Termina por ello en el sentimiento de la más absoluta soledad y orfandad, borrado por el obispo/padre y repudiado por el marqués y la loca-cuerda Dulce Olivia por considerar que su relación con Sierva María era para "saciar" sus "apetitos satánicos". Pero, fundamentalmente, su desdicha obedece al hecho de sentirse abruptamente separado del objeto del deseo, a causa de su cobardia y los formalismos legales. Gracias a Sierva María, Cayetano entrevió otro mundo, pleno de vitalidad, opuesto a "la religión de la muerte" (DA: 195) que ha profesado. Experimentó que "amar es combatir, si dos se besan/el mundo cambia, encarnan los deseos”, que el mundo cambia/si dos se miran y se reconocen" 40 . Pero no se transfiguró como sí lo hizo Sierva María quien, al final, es encontrada "muerta de amor en la cama con los ojos radiantes y la piel de recién nacida" (DA: 198).

\section{GEOMETRIJA POŽELENJA V TREH LJUBEZENSKIH ZGODBAH}

Nekateri kritiki menijo, da roman kot zvrst $\mathrm{v}$ nekaj stoletjih ne bi dosegel današnje stopnje razvoja brez ljubezni in njenih zapletov. Zato je morda nesmiselno poudarjati, da je prav ljubezen najpogostejša tema celotnega pripovednega opusa Gabriela Garcie Márqueza. Čeprav omenjena tematika bolj izstopa v njegovih zadnjih romanih (beseda ljubezen se pojavlja celo v naslovih), je ljubezen prisotna že v njegovih zgodnjih pripovednih delih.

Pričujoči članek želi analizirati tri različne zgodbe, $v$ katerih je pisatelj izpostavil temo ljubezni: $v$ kratki zgodbi "Smrt vztraja onkraj ljubezni" ("Muerte constante más allá del amor") in v romanih "Ljubezen v času kolere" ter "O ljubezni in drugih demonih".

\footnotetext{
39 "La lectura fragmentaria de los sonetos de Garcilaso, el tópico más alto de la idealización del amor, acompaña el juego erótico de los amantes desacralizando y pervirtiendo el texto primero" (Blanca Inés Gómez, Intertextualidad y erotismo en Del amor y otros demonios". XX Congreso Nacionalde Linguistica y Literatura. Bogotá, Instituto Caro y Cuervo/Universidad Nacional, 1998: 237 Octavio Paz, "Piedra de sol", Libertad bajo palabra, México. Fondo de Cultura Económica, 1981: 248.
} 